\title{
Impaired antiviral activity of interferon alpha against hepatitis $C$ virus $2 a$ in Huh-7 cells with a defective Jak-Stat pathway
}

\author{
Sidhartha Hazari ${ }^{1}$, Partha K Chandra', Bret Poat ${ }^{1}$, Sibnarayan Datta' ${ }^{1}$, Robert F Garry ${ }^{2}$, Timothy P Foster ${ }^{3}$, \\ Gus Kousoulas ${ }^{3}$, Takaji Wakita ${ }^{4}$, Srikanta Dash ${ }^{1 *}$
}

\begin{abstract}
Background: The sustained virological response to interferon-alpha (IFN- $\alpha$ ) in individuals infected with hepatitis $C$ virus (HCV) genotype 1 is only $50 \%$, but is about $80 \%$ in patients infected with genotype 2-6 viruses. The molecular mechanisms explaining the differences in IFN- $\alpha$ responsiveness between HCV 1 and other genotypes have not been elucidated.

Results: Virus and host cellular factors contributing to IFN responsiveness were analyzed using a green fluorescence protein (GFP) based replication system of HCV 2a and Huh-7 cell clones that either possesses or lack a functional Jak-Stat pathway. The GFP gene was inserted into the C-terminal non-structural protein 5A of HCV $2 a$ full-length and sub-genomic clones. Both HCV clones replicated to a high level in Huh-7 cells and could be visualized by either fluorescence microscopy or flow cytometric analysis. Huh-7 cells transfected with the GFP tagged HCV 2a genome produced infectious virus particles and the replication of fluorescence virus particles was demonstrated in naïve Huh-7.5 cells after infection. IFN- $\alpha$ effectively inhibited the replication of full-length as well as sub-genomic HCV 2a clones in Huh-7 cells with a functional Jak-Stat pathway. However, the antiviral effect of IFN- $\alpha$ against HCV $2 a$ virus was not observed in Huh-7 cell clones with a defect in Jak-Stat signaling. HCV infection or replication did not alter IFN- $\alpha$ induced Stat phosphorylation or ISRE promoter-luciferase activity in both the sensitive and resistant Huh-7 cell clones.

Conclusions: The cellular Jak-Stat pathway is critical for a successful IFN- $\alpha$ antiviral response against HCV 2a. HCV infection or replication did not alter signaling by the Jak-Stat pathway. GFP labeled JFH1 2a replicon based stable cell lines with IFN sensitive and IFN resistant phenotypes can be used to develop new strategies to overcome IFNresistance against hepatitis $C$.
\end{abstract}

\section{Background}

Hepatitis $\mathrm{C}$ virus (HCV) is the most common bloodborne infection affecting the liver. Chronic HCV infection often leads to the development of liver cirrhosis and cancer [1]. HCV infection often does not present early symptoms and thus can go undetected while significant liver damage sets in over the course of 10-20 years. There are 180 million people currently infected with $\mathrm{HCV}$ worldwide $[2,3]$. The incidence of new $\mathrm{HCV}$ infection is increasing each year, creating a significant

\footnotetext{
* Correspondence: sdash@tulane.edu

'Department of Pathology and Laboratory Medicine, Tulane University of Health Sciences Center, 1430 Tulane Ave, New Orleans, LA 70112, USA
}

public health problem. The standard treatment for chronic $\mathrm{HCV}$ infection is interferon with ribavirin, but many patients infected with certain viral strains develop resistance to treatment $[4,5]$. The mechanisms of interferon action and resistance in chronic HCV infection are currently not well understood. Development of efficient $\mathrm{HCV}$ cell culture systems for all major $\mathrm{HCV}$ strains is required to understand the role of host-virus interaction in the IFN-antiviral response.

$\mathrm{HCV}$, a member of the Flaviviridae, is an enveloped virus containing a single-stranded positive sense RNA genome approximately 9600 nucleotides in length [6,7]. The nucleotide sequences of $\mathrm{HCV}$ genomes isolated in different parts of world vary considerably and are quite

\section{() Biomed Central}


heterogeneous. There are six major genotypes and numerous sub-types of $\mathrm{HCV}$ that have been described from all over the world [8-10]. Genotype 1 (subtype 1a and $1 \mathrm{~b}$ ) is the most common in the United States, followed by genotype 2 and 3 [10,3]. Genotype 3 is most common in the Indian subcontinent [8]. Genotype 4 is the most common genotype in Africa and the Middle East [11]. Genotypes 5 and 6 are most common and predominant in South Africa and Southeast Asia [12].

In spite of high sequence variability among different $\mathrm{HCV}$ genotypes, the genomic organization of all $\mathrm{HCV}$ strains starts with a highly conserved untranslated sequences (called 5' UTR), followed by a large open reading frame, and terminating with 3'-untranslated sequences. The large polyprotein is processed by cellular and viral proteases into structural proteins (core, E1, and E2) and nonstructural proteins (p7, NS2, NS3, NS4A, NS4B, NS5A, and NS5B). The nonstructural proteins NS3 to NS5B are essential for RNA replication and have distinct functions in the HCV life cycle. The 5' and 3' UTR sequences of HCV contain numerous cisacting signals that are absolutely required for RNA translation and replication as shown by in vitro experiments using the cell culture system. Despite the high nucleotide sequence homology of the 5' and 3' UTRs among all genotypes of $\mathrm{HCV}$, the efficiency of RNA genome replication of different $\mathrm{HCV}$ strains in the cell culture varies significantly [13]. Some strains of HCV with adaptive mutations replicate efficiently in the cell culture, whereas others do not require any adaptive mutations. The best example is the JFH1 clone of $\mathrm{HCV}$ 2a strain that replicates to a higher level in cell culture and generates more infectious virus particles compared to all other full-length infectious clones [14-16]. These observations suggest that HCV genetics and host cellular environments are the two major determinants of the efficacy of HCV replication and its response to antiviral therapy.

Interferon alpha (IFN- $\alpha$ ) along with ribavirin has been widely used as a standard treatment option for patients with chronic HCV infection all over the world [3]. However, the sustained virological response to IFN- $\alpha$ in individuals infected with $\mathrm{HCV}$ genotype 1 is only $50 \%$ as compared with $80 \%$ in patients infected with genotype 2 to 6 viruses [17]. Molecular mechanisms explaining why certain genotype viruses respond better to IFN- $\alpha$ than others have not been elucidated. We have shown that IFN- $\alpha$ effectively inhibits the IRES mediated translation of all HCV strains in the cell culture, indicating that differential resistance is not due to IRES sequence heterogeneity [18-20]. To gain an insight into the mechanisms of IFN resistance in the $\mathrm{HCV}$ cell culture model, we have developed Huh-7 cell lines in which the HCV $1 \mathrm{~b}$ Con1 strain is resistant to IFN, after prolonged IFN- $\alpha$ treatment of a low inducer Huh-7 replicon cell line $[21,22]$. We demonstrated that phosphorylation of Stat1 and Stat 2 proteins in the IFN-resistant replicon cell lines is blocked due to reduced phosphorylation of Jak1 and Tyk2 proteins [21,22]. These studies provided direct evidence that a defective Jak-Stat pathway makes $\mathrm{HCV}$ replication resistant to interferon treatment in a replicon cell line, and indicated that cellular factors are important for determining the response of $\mathrm{HCV}$ to IFN- $\alpha$ treatment. To extend our observations, we have examined the replication and anti-viral response of an IFNsensitive $\mathrm{HCV} 2 \mathrm{a}$ virus clone in a Huh-7 clone with a defective Jak-Stat pathway. For this purpose, we first developed a chimeric clone between GFP and a highly efficient $\mathrm{HCV} 2 \mathrm{a}$ virus. Insertion of the GFP coding sequences into HCV 2a allowed us to study a high level replication of the virus in Huh-7 cells directly by fluorescence microscopy or flow cytometric analysis. We also determined that replication of $\mathrm{HCV} 2 \mathrm{a}$ can only be inhibited by IFN- $\alpha$ in a dose dependent manner in Huh-7 cells with a functional Jak-Stat pathway. Replication of the full-length and sub-genomic clone of a HCV 2a strain was not inhibited by IFN- $\alpha$ in $\mathrm{Huh}-7$ cell clones with a defective Jak-Stat pathway. Infection with full-length virus or stable replication of sub-genomic HCV RNA did not alter the state of Jak-Stat signaling or interferon sensitivity in these two different Huh-7 clones. We have now developed multiple GFP tagged $\mathrm{HCV}$ sub-genomic replicon cell clones in which replication of $\mathrm{HCV}$ are totally resistant to IFN- $\alpha$. We believe that these cell clones can be used to understand the cellular basis of IFN-resistance in a cell culture as well as develop alternative strategies to overcome mechanisms of resistance.

\section{Materials and methods \\ Cell culture}

Huh-7.5 cells, obtained from the laboratory of Dr. Charles M. Rice (Center for the Study of Hepatitis C, The Rockefeller University, New York), were cultured at $37^{\circ} \mathrm{C}$ in Dulbecco's modified Eagle's medium supplemented with $2 \mathrm{mM}$ l-glutamine, nonessential amino acids, $100 \mathrm{U} / \mathrm{ml}$ of penicillin, $100 \mu \mathrm{g} / \mathrm{ml}$ of streptomycin and $10 \%$ fetal bovine serum, under $5 \% \mathrm{CO}_{2}$ conditions. Interferon resistant ( $\mathrm{R}-24 / 1)$ replicon cells were generated in our laboratory by prolonged treatment of low inducer replicon cell lines (Con-15, Con-17, and Con$24)$ with IFN- $\alpha$ as described previously [21,22]. A cured Huh-7 cell line with defective Jak-Stat pathway (R-Huh7) was prepared from IFN- $\alpha$ resistant replicon cell line (R-24/1) after repeated treatment with cyclosporine-A $(1 \mu \mathrm{g} / \mathrm{ml})$ as described previously [22]. Interferon sensitive cured Huh-7 cells (S-Huh-7) were derived from the 5-15 replicon cell line after treatment with IFN- $\alpha$. 
Interferon sensitive and interferon resistant phenotypes in the cured S-Huh-7 and R-Huh7 cells were examined by measuring their ability to activate the ISRE-luciferase promoter in the presence of exogenous IFN- $\alpha$. The expression of functional Jak-Stat signaling proteins in these cells after IFN- $\alpha$ treatment was examined by western blot analysis of phosphorylated Stat1 and Stat2. All the resistant cell lines have defects in the phosphorylation of Stat1 and Stat2 protein, whereas the S-Huh-7 clone showed a high level of phosphorylation of Stat1 and Stat 2 proteins within 30 minutes of IFN- $\alpha$ treatment [22]. All Huh-7 cell lines were maintained in Dulbecco's modified Eagle's medium supplemented with 2 mM l-glutamine, nonessential amino acids, $100 \mathrm{U} / \mathrm{ml}$ of penicillin, $100 \mu \mathrm{g} / \mathrm{ml}$ of streptomycin and $5 \%$ fetal bovine serum.

\section{Construction of full-length and sub-genomic JFH1 2a chimeric clones}

The JFH1 full-length cDNA clone of HCV 2a strain which was isolated from a chronically infected Japanese fulminant hepatitis patient was obtained from Wakita and his coworkers [14]. Chimeric clones between JFH1 and enhanced green fluorescent protein (EGFP) were constructed in our laboratory by the standard overlapping PCR amplification and cloning methods. The coding sequence of GFP was amplified from pEGFP-N1 plasmid and inserted in-frame of the NS5A coding sequence of the JFH1 cDNA clone between 2394 and 2395 amino acids position (between 417 and 418 amino acids of the NS5A protein). The PCR amplification of recombinant DNA and cloning was performed in four different steps. In the first step, the $228 \mathrm{bp}$ (F1) recombinant DNA fragment containing 70 amino acids of NS5A (nts.73397546) fusion with the first 6 amino acids of EGFP-N1 was amplified using a sense primer (S/7336-7360/HCV5'-CCTCCCCCAAGGAGACGCCGGACA-3') and antisense primer (AS/7529/HCV-5'CTCGCCCTTGCTCACCATG GGGGGCATAGAGGAGGC-3'). In the second step, the 719 bp (F2) recombinant DNA fragment containing the total EGFP-N1 open reading frame (ORF) fused with the $\mathrm{N}$ - and C-termini of HCV NS5A was amplified using sense and anti-sense overlapping primers (S/7529/GFP- 5'-GCCTCCTCTATGCCCCCCATGGTGAGC AAGGGCGAG-3' and (AS/7547-7564/GFP 5'TCCAGGCTCCCCCTCGAGCTTGTACA

GCTCGTCCAT-3'). In the third step, the recombinant 531 bp DNA fragment (F3) containing last 6 amino acids of EGFP-N1 and 177 amino acids of NS5A (nt. 75478077) was amplified by using sense primers (S/7547/ HCV- 5'-ATGGACGAGCTGTACAAG CTCGAGGGGGAGCCTGGA-3') and anti-sense primer (AS/80598077/HCV-5'-GTCTTCCAGGAGGTCCTTCCACAC-
3'). In fourth step, the F1, F2 and F3 PCR fragments were assembled into the 1478 bp DNA fragment through overlapping PCR. In the final step, the recombinant DNA was digested with restriction enzyme RsrII and HpaI, gel purified and then ligated with pJFH1 clone using the unique RsrII and HpaI restriction sites present in the NS5A gene. The resulting plasmid was named pJFH1-GFP. The recombinant plasmid was amplified and the construction was confirmed by sequence analysis. A full-length pJFH1-GFP plasmid clone was prepared with a GDD to GND mutation in the NS5B gene to use as a control (pJFH1-GND-GFP) in the replication assay. A full-length pJFH1-GFP plasmid was also prepared with a deletion in the E1-E2 gene (pJFH1- $\triangle \mathrm{E} 1 \mathrm{E} 2-\mathrm{GFP})$ to use as a control in the infectivity assay. To generate a sub genomic GFP replicon clone of $\mathrm{HCV} 2 \mathrm{a}$, the recombinant plasmid containing the NS5A and EGFP-fusion was excised from full-length pJFH1-GFP plasmid using the NsiI and HpaI enzyme and re-cloned into the pSGR replicon [23]. This chimeric clone was named pSGR-GFP. As a control, we created a mutant construct pSGR-GND-GFP clone with a point mutation that changes a GDD motif to GND, abolishing the RNA polymerase activity of the NS5B protein. All the recombinant plasmids constructs were confirmed by DNA sequence analysis.

\section{In-vitro RNA synthesis}

Full-length (pJFH1-GFP) and sub-genomic replicon (pSGR-GFP) plasmids were linearized with XbaI restriction enzyme and purified by phenol chloroform extraction and precipitated by ethanol. The HCV full length and sub-genomic RNAs were transcribed from XbaI linearized plasmid DNA templates using the MEGA-script T7 kit (Ambion, Austin, TX, USA). In vitro transcribed RNA was treated with DNase I to eliminate any residual plasmid DNA, extracted with phenol and chloroform, and then precipitated with absolute ethanol. The RNA pellet was re-suspended in nuclease free water and 10 $\mu \mathrm{g}$ aliquots of this RNA were stored at $-80^{\circ} \mathrm{C}$. The integrity of in vitro transcribed RNA was verified by agarose gel electrophoresis.

\section{RNA transfection}

Huh-7.5, S-Huh-7 and R-Huh-7 cells were electroporated with in vitro transcribed HCV RNA using a standard protocol described previously [17]. Briefly, cells were harvested using trypsin-EDTA, pelleted by centrifugation and washed in $10 \mathrm{ml}$ of phosphate buffered saline (PBS). The cell pellet was suspended in PBS $\left(10^{7}\right.$ cells per ml). Ten micrograms of in vitro transcribed RNA was mixed with $400 \mu \mathrm{l}$ of Huh-7 cell suspension in a cuvette $(0.4 \mathrm{~cm}$, Bio-Rad) and subjected to an electric pulse at $960 \mu \mathrm{F}$ and 270 volts using a gene pulser 
apparatus (Bio-Rad). Following electroporation, cells were diluted in $10 \mathrm{ml}$ of complete medium and plated in a $100-\mathrm{mm}$ diameter cell culture dish.

\section{Replication assay}

To study replication of full-length HCV-GFP chimeric RNA, the electroporated Huh-7 cells were cultured in a $100-\mathrm{mm}$ plate with regular growth medium. The expression of GFP in the transfected Huh-7 cells was recorded at $0,24,48,72$ and 96 hours post-transfection. To study the replication of HCV sub-genomic RNA, stable Huh-7 cells replicating sub-genomic RNA were prepared. Cured Huh-7 cells derived from interferon sensitive (SHuh-7) and resistant replicon cell lines (R-Huh-7) in our laboratory were used. Huh-7 cells electroporated with sub-genomic RNA were cultured in a growth medium supplemented with $500 \mu \mathrm{g} / \mathrm{ml} \mathrm{G}-418$ drug. These cells were maintained with a regular medium change at every three days for 3-4 weeks until distinct G-418 resistant cell colonies were developed. To make a stable cell line replicating HCV 2a sub-genomic RNA, multiple G418 resistant cell clones were isolated and cultured in medium supplemented with $1 \mathrm{mg} / \mathrm{ml} \mathrm{G}$-418. In these stable cell lines absence of HCV plasmid DNA integration was confirmed by direct PCR followed by Southern blot analysis for the neo gene (sense 5'-ATCGAATTCATCGTGGCTGGCCA-3'; anti-sense 5'-CTAGAATTCGGCGCGAGCCCCTG-3'; probe 5'GCTTGGTGGTCGAATGGGCAG GTAGCCGGA-3’.

\section{Infectivity assay}

An infectivity assay for $\mathrm{HCV}$ was performed using a published protocol [15]. Huh-7.5 cells were transfected with $20 \mu \mathrm{g}$ of in vitro transcribed full-length JFH1-GFP RNA by electroporation method. After $72 \mathrm{~h}$, cells were collected by scraping and then lysed by four rounds of freeze-thaw cycles. The cell lysates were clarified by centrifugation at $3400 \mathrm{rpm}$ for five minutes. The clear supernatant was collected and the titer of $\mathrm{HCV}$ in the supernatant was determined by real-time RT-PCR using a primer set targeted to the 5'UTR. A tissue culture infective dose (TCID50) was determined using 10-fold serial dilution of the virus containing supernatant on 2well Lab-Tek chamber slides (Nalge Nunc International, Rochester, New York). Briefly, Huh-7.5, S-Huh-7 and RHuh-7 cells were seeded on a 2-well glass chamber slide at a density of $1 \times 10^{4}$ cells per well. The next day, the culture medium was removed and $1-\mathrm{ml}$ of serial dilutions of culture supernatant containing infectious virus was added to the wells. The cells were incubated overnight at $37^{\circ} \mathrm{C}$. On the following day the culture medium was removed, and the cells were washed once using PBS and then incubated in fresh complete medium. After 96 hours post-transfection, the cells were removed, washed in PBS, fixed in 4\%-parformaldehyde for 30 minutes and then counter stained with Hoechst dye (H33342, Calbiochem, Darmstadt, Germany) for 15 minutes at $37^{\circ} \mathrm{C}$. Cells were examined at $484 \mathrm{~nm}$ using a fluorescence microscope (Olympus) for expression of green fluorescence. Cells were then examined at $340 \mathrm{~nm}$ for blue nuclear staining. For each area, two sets of pictures were taken. The final image was generated by superimposing blue nuclear fluorescence of Hoechst dye with green fluorescence of GFP using Abode Photoshop software (V 7.0). The numbers of green positive cells in ten different fields were counted and the percentage of green fluorescence positive cells in the culture was determined. The dilution of virus-containing supernatant that showed 50\% GFP positive cells 96 hours after infection in the culture (called the TCID50) was determined. The MOI of the infectious culture supernatants was determined by dividing the TCID50 with the cell number used in the infectivity assay.

\section{Interferon treatment}

To study the effect of interferon on the full-length $\mathrm{HCV}$ 2a clone, transfected or infected Huh-7 cells were treated with increasing concentrations of IFN- $\alpha$ (Intron A, Schering-Plough, NJ, USA). The antiviral effect of IFN- $\alpha$ against $\mathrm{HCV}$ using different Huh-7 clones was confirmed by observing GFP expression under a fluorescence microscope or by flow cytometric analysis, and HCV RNA levels was measured by RPA.

\section{Ribonuclease protection assay (RPA)}

Total RNA was prepared from the cell pellet by the GITC method and subjected to RPA for the detection of genomic positive-strand HCV RNA. For RPA experiments, $25 \mu \mathrm{g}$ of the total RNA was mixed with a negative-strand RNA probe targeted to the 5'UTR of HCV $\left(1 \times 10^{6} \mathrm{cpm}\right)$ in a $10 \mu \mathrm{l}$ hybridization solution, denatured for 3 minutes at $95^{\circ} \mathrm{C}$ and then hybridized overnight at $50^{\circ} \mathrm{C}$. RNase digestion was performed in $200 \mu \mathrm{l}$ of RNase digestion buffer (10 mM Tris, pH 7.5, $5 \mathrm{mM}$ EDTA and $0.3 \mathrm{M} \mathrm{NaCl}$ ) containing RNaseA/T1 cocktail at 1:100 dilutions (Ambion Inc., Austin, TX) for an hour at $37^{\circ} \mathrm{C}$. Then the sample was treated with $2.5 \mu \mathrm{l}$ of $25 \%$ SDS and $10 \mu \mathrm{l}$ of proteinase $\mathrm{K}(20 \mathrm{mg} / \mathrm{ml})$ for $15 \mathrm{~min}$ utes. Samples were extracted with phenol and chloroform and then precipitated after addition of 2.5 volumes of absolute ethanol. The pellet was obtained by centrifugation for 30 minutes at 12,000 rpm. The RNA pellet was washed with $70 \%$ ethanol, suspended in $8 \mu \mathrm{l}$ of gel loading buffer, boiled for one minute and separated on a $6 \%$ polyacrylamide TBE-Urea gel (Invitrogen, Carlsbad, CA). The gel was dried and exposed to X-ray film (Kodak Biomax-XAR, Rochester, NY). We prepared a plasmid construct called pCR-II (2a), which contained 
the 79-297 nucleotides of the 5'UTR sequence of the JFH1 clone (pCR-II NT-218) (Invitrogen). This plasmid was linearized with HindIII restriction enzyme and a positive strand RNA probe was prepared using T7 RNA polymerase in the presence of 32p labeled CTP. Likewise, this plasmid was linearized with $\mathrm{XbaI}$ restriction enzyme and Sp6 RNA polymerase was used to prepare a negative strand RNA probe for the detection of a positive strand HCV RNA. The same amounts of the RNA extracts were subjected to RPA for GAPDH mRNA. We used a linearized pTRI-GAPDH-human anti-sense control template to prepare a probe to detect GAPDH mRNA using Sp6 RNA polymerase (Ambion Inc., Austin, TX). The appearance of 218 (HCV 2a) and 317 nts protected fragments indicated the presence of the $\mathrm{HCV}$ positive-strand and the GAPDH mRNA, respectively.

\section{Flow analysis}

The percentage of Huh-7 cells expressing GFP after transfection with full-length GFP-RNA transfected cells was analyzed by flow cytometric analysis. Cells were transfected with $10 \mu \mathrm{g}$ of in vitro transcribed RNA in 6well plates, and harvested by treatment with trypsinEDTA at 24, 48, 72 and 96 hours post-transfection. The cells were pelleted by centrifugation at $500 \mathrm{rpm}$ in a refrigerated centrifuge. The cell pellet was resuspended in $4 \%$ paraformaldehyde for 30 minutes, and washed twice in $10 \mathrm{ml}$ of PBS using centrifugation. After this step, the cell pellet was resuspended in $1 \mathrm{ml}$ of PBS and analyzed by flow cytometer (BD-Biosciences). The percentage of GFP expressing cells in the replicon culture was determined by flow analysis using the identical procedure. Stable replicon cells after interferon treatment were harvested by trypsin-EDTA treatment and analyzed by flow cytometry.

\section{Real-time RT-PCR}

Real time RT-PCR was performed to quantify HCV RNA levels in the infected cell culture using a published protocol [24]. The $243 \mathrm{bp} \mathrm{HCV} \mathrm{DNA} \mathrm{was} \mathrm{amplified}$ from the RNA extract by reverse transcription polymerase chain reaction using the outer sense (OS) primer 5'GCAGAAAGCGCCTAGCCATGGCGT-3' (67-90) and outer anti-sense (OAS) primer 5'-CTCGCAAGCGCCCTATCAGGCAGT-3' (287-310). First the complementary DNA synthesis was performed from positive strand HCV-RNA using an outer anti-sense primer (OAS) targeted to the highly conserved 5'UTR region of HCV in $20 \mu \mathrm{l}$ volume. Briefly, $2 \mu \mathrm{gm}$ of total cellular RNA were mixed with $1 \mu \mathrm{l}$ OAS primer $(200 \mathrm{ng} / \mu \mathrm{l})$, denaturized at $65^{\circ} \mathrm{C}$ for 10 minutes and annealed at room temperature. Avian myeloblastosis virus (AMV) reverse transcriptase $(10 \mathrm{U})$ (Promega, Madison, WI) was added and incubated at $42^{\circ} \mathrm{C}$ for 60 minutes in the presence of 50 $\mathrm{mmol} / \mathrm{L}$ Tris, $\mathrm{pH}$ 8.3, $50 \mathrm{mmol} / \mathrm{L}$ ethylenediaminetetraacetic acid (EDTA), $500 \mathrm{nmol} / \mathrm{L} \mathrm{dNTP}, 250 \mathrm{nmol} / \mathrm{L}$ spermidine, and $40 \mathrm{U}$ RNasin (Promega). The cDNA was stored at $-20^{\circ} \mathrm{C}$ until use. SYBR Green real time PCR amplification was performed in $20 \mu \mathrm{l}$ of volume containing $10 \mu \mathrm{l}$ of SYBR Green ER qPCR SuperMix, $1 \mu \mathrm{l}(250$ $\mathrm{ng} / \mathrm{ul}$ ) of sense and antisense primer with $4 \mu \mathrm{l}$ of cDNA and $4 \mu \mathrm{l}$ of distilled water. All samples were run in triplicate. The amplification was carried out using the standard program recommended by Bio-Rad Laboratory that includes: $50^{\circ} \mathrm{C}$ for 2 minutes, $95^{\circ} \mathrm{C}$ for 8 minutes, then additional 50 cycles wherein each cycle consists of a denaturation step at $95^{\circ} \mathrm{C}$ for 10 seconds, and annealing and extension step at $60^{\circ} \mathrm{C}$ for 30 seconds. At the end of the amplification cycles, melting temperature analysis was performed by a slow increase in temperature $\left(0.1^{\circ} \mathrm{C} / \mathrm{s}\right)$ up to $95^{\circ} \mathrm{C}$. Amplification, data acquisition, and analysis were performed on CFX96 Real Time instrument (Bio Rad) using CFX manager software (Bio Rad).

\section{Results \\ High-level replication of pJFH1-GFP chimera clone in Huh-7.5 cells}

Replication of the full-length HCV 2 a genome is possible due to the availability of the JFH1 cDNA clone. However, the highly sensitive RT-PCR and immunodetection methods are most often needed to detect replication of $\mathrm{HCV}$ in the transfected cells. To overcome the technical difficulties associated with the detection of the full-length viral RNA replication, we constructed chimeric clones of the JFH1 clone and GFP so that replication of whole viral genome in the transfected cells could be examined by fluorescence microscopy. Previous reports suggest that heterologous sequences can be inserted into the HCV genome without altering its ability to replicate [25-28]. The coding sequence of GFP was inserted into C-terminus of the NS5A protein of $\mathrm{HCV}$ at the 2394 amino acid position. Chimeric clones of GFP and full-length, and a sub-genomic replicon of HCV 2a were prepared (Fig. 1). The N-terminal and Cterminal fusion of HCV NS5A with EGFP protein was confirmed by sequence analysis. To study the replication of full-length virus, in vitro transcribed RNA derived from wild type and GND-mutant clone were electroporated into Huh-7.5 cells. The expression of GFP was recorded in a kinetic study. The replication of fulllength JFH1-GFP chimera in the transfected Huh-7.5 cells was seen as early as 24 hour post-transfection and the number of GFP positive cells in the culture increased gradually at 48, 72 and 96 hours (Fig 2A). In contrast, replication of the JFH1-GND-GFP mutant RNA in Huh-7.5 cells was not observed at 48, 72 or 96 hours post-transfection, while only a very faint GFP 
signal was seen in Huh-7.5 cells at 24 hours post-transfection (Fig. 2B). The efficiency of replication of chimeric clones in Huh-7.5 cells after RNA transfection was observed in approximately $8 \%$ of cells as examined by flow cytometry (Fig. 2C and 2D). Replication of fulllength JFH1-GFP chimera clone was confirmed by examining $\mathrm{HCV}$ positive and negative strand RNA levels by RPA assay. The levels of HCV RNA in the full-length transfected cells and GND mutant transfected cells were clearly different (Fig 3A). As expected, the levels of mutant RNA dropped below the input level and remained undetected at 48, 72 and 96 hours post-transfection. The level of HCV positive strand RNA seen in the RPA assay appeared to be higher at an earlier time point in the full-length transfected cells at a later time point. This may be due to an input RNA carryover during the transfection step. There was a good correlation between the amount of HCV RNA and expression of GFP at later time points.

$\mathrm{HCV}$ is a positive strand RNA virus that replicates via the synthesis of negative strand RNA. To demonstrate that the replication of transfected RNA resulted in the production of negative strand RNA in the transfected cells, RPA for negative strand HCV RNA was performed in the transfected cells at 0, 24, 48, 72 and 96 hours post-transfection. Negative strand HCV RNA was not detectable at the zero-time point but appeared at 24

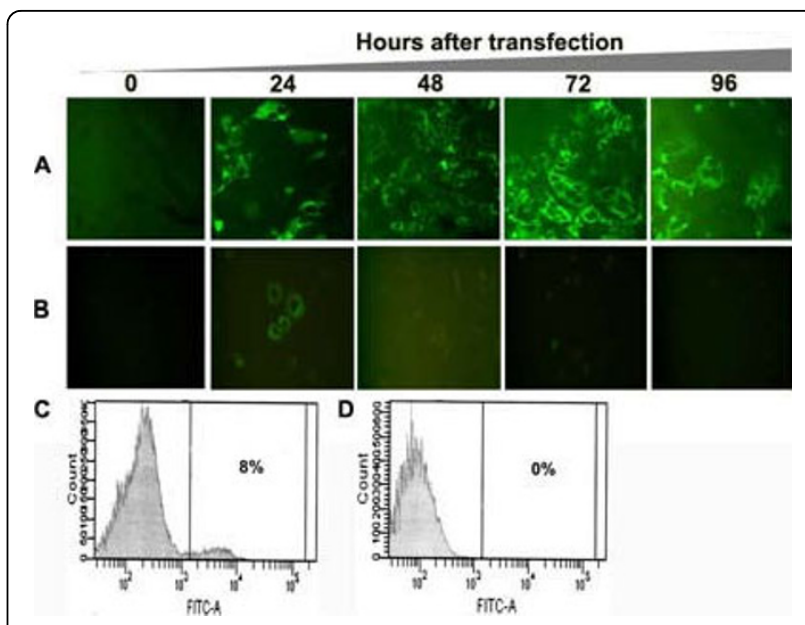

Figure 2 Replication of JFH1-GFP full-length RNA and JFH1GND-GFP mutant RNA in Huh-7.5 cells after transfection. Huh7.5 cells were electroporated with $10 \mu \mathrm{g}$ of in vitro transcribed RNA prepared either from full-length or GND mutant plasmid. Intracellular expression of GFP in the transfected culture was examined under a fluorescence microscope. (A) Intracellular GFP expression in Huh-7.5 cells transfected with JFH1-GFP RNA at 0, 24, 48,72 and 96 hours. (B) Intracellular expression of GFP in Huh-7.5 cells transfected with JFH1-GND-GFP mutant RNA at 0, 24, 48, 72 and 96 hours. (C) Intracellular GFP expression measured by flow cytometry in the Huh-7.5 cells transfected with JFH1-GFP RNA after 72 hours. (D): Intracellular GFP expression measured by flow cytometry in the transfected cells of JFH1-GND-GFP mutant RNA after 72 hours.

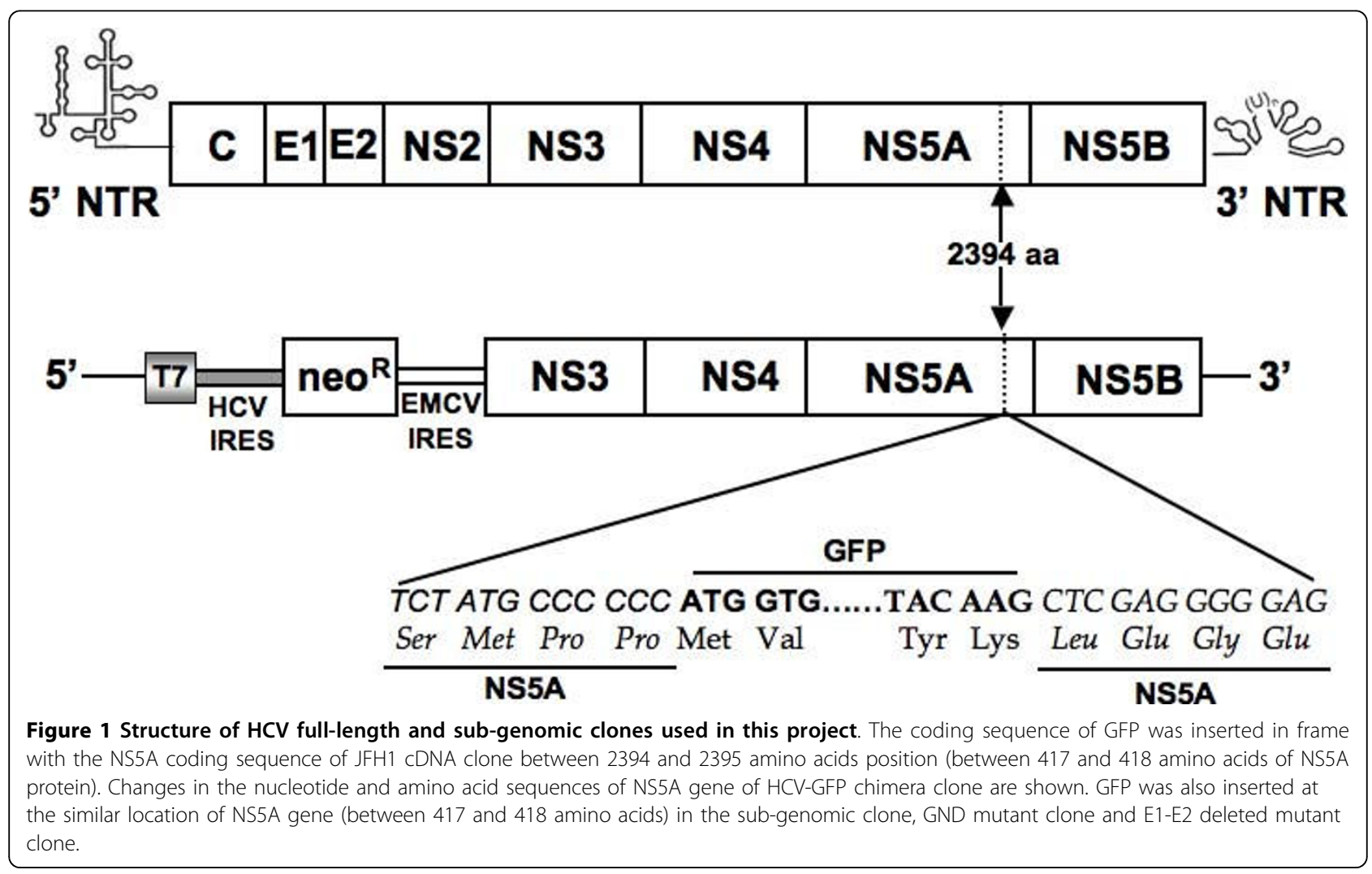




\section{A. Positive strand HCV RNA}

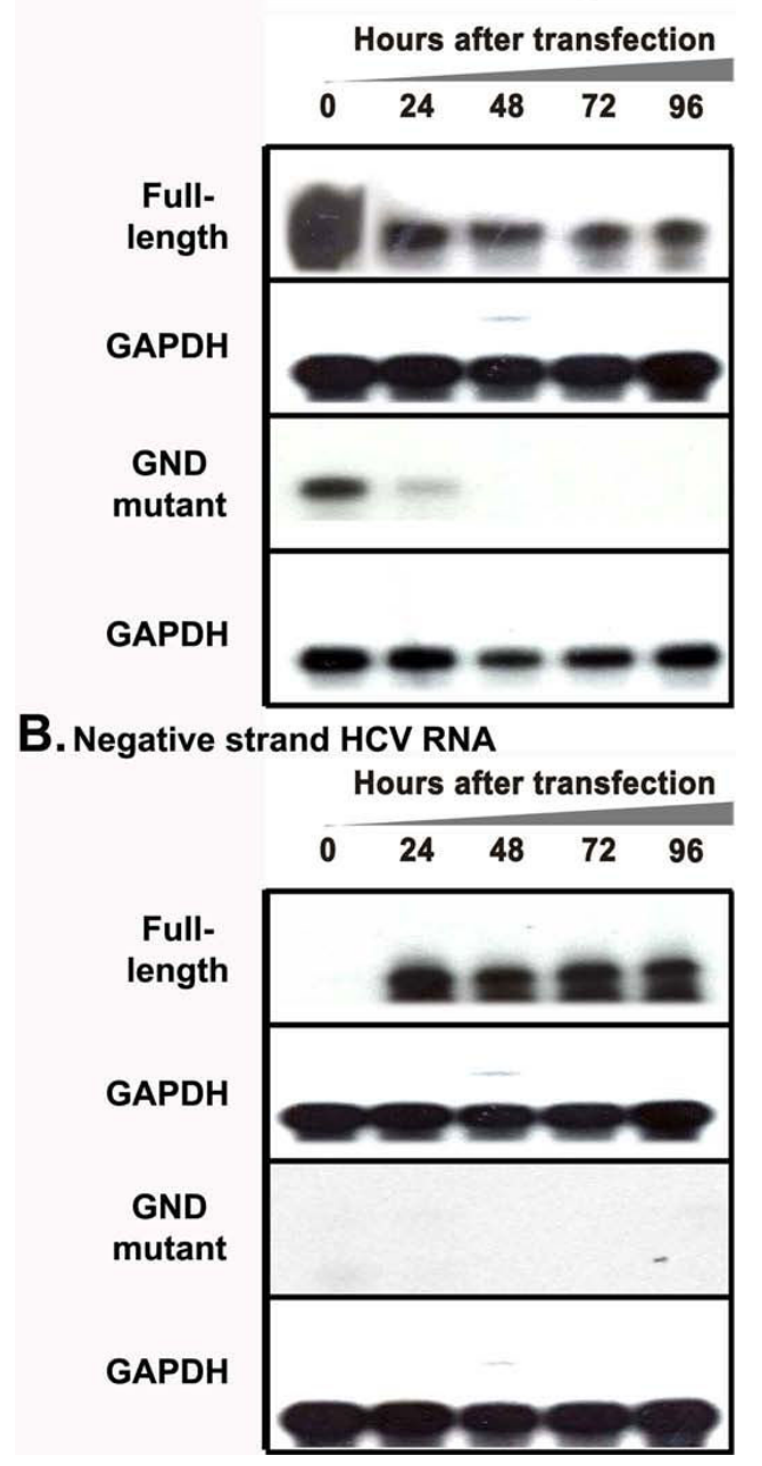

Figure 3 Detection of positive and negative strand HCV RNA in the transfected Huh 7.5 cells by RPA. Huh-7.5 cells were transfected with $10 \mu \mathrm{g}$ of in vitro transcribed full-length JFH1-GFP and JFH1-GND-GFP mutant HCV RNA by electroporation. Total RNA was isolated from the RNA transfected cell culture at 0, 24, 48, 72 and 96 hours post-transfection. For the detection of positive strand HCV RNA, total cellular RNA was hybridized with a negative strand RNA probe targeted to the highly conserved $5^{\prime} U T R$ region and then RPA experiment was performed. For the detection of negative strand RNA, total cellular RNA was hybridized with a positive sense RNA probe targeted to the $5^{\prime} \mathrm{UTR}$ region and then RPA was performed. (A) Intracellular HCV positive strand RNA in the Huh-7.5 cells transfected with full-length and mutant JFH1-GFP RNA at 0, 24, 48,72 and 96 hours post-transfection. GAPDH mRNA levels was used as a loading control. (B) Replicative negative strand HCV-RNA in Huh-7.5 cells transfected with JFH1-GFP and JFH1-GND-GFP mutant RNA. The bottom panel shows the intracellular GAPDH mRNA level indicating that equal amounts of RNA were loaded in each well in the RPA assay. hour post-transfection (Fig. 3B). Negative strand RNA was undetectable in Huh-7.5 cells transfected with GND mutant RNA. The presence of negative strand $\mathrm{HCV}$ RNA in the full-length transfected cells confirmed active replication of virus in the culture. Based on the results of these experiments we conclude that the chimeric JFH1-GFP clone is replication competent.

To examine infectious virus particle production from cells transfected with JFH1-GFP chimera RNA, an infectivity assay was performed. Culture supernatants were collected from transfected cells, clarified by centrifugation and inoculated to Huh-7.5 cells. The infectivity of $\mathrm{HCV}$ was confirmed by direct examination of infected cells under a fluorescence microscope and HCV RNA levels were measured by real-time RT-PCR assay. Infectivity of culture supernatants from cells transfected with full-length and E1-E2 deleted mutant clone was determined by measuring intracellular GFP expression. There was an increase in the number of GFP positive cells after 24, 48 and 72 hours suggesting the replication of HCV RNA after natural infection (Fig. 4A). No GFP expression was observed in Huh-7.5 cells infected with supernatants derived from cells transfected with E1-E2 deleted mutant HCV RNA (Fig. 4B). To confirm that the expression of $\mathrm{HCV}$ in the infected cells is associated with the increase in viral RNA, the titer of HCV positive strand RNA was measured using a real-time RT-PCR. The level of HCV RNA in the infected cell cultures was increased from 24 to 72 hours suggesting the replication of HCV-RNA genome in the infected culture (Fig. 4C). Thus, JFH1-GFP-tagged HCV RNA genome is able to replicate in Huh-7.5 cells after transfection and generates an infectious virus.

\section{High-level replication of GFP labeled sub-genomic RNA of} HCV 2a clone

Since the JFH1 2a clone replicates to a high level in a cell culture without adaptive mutations, we attempted to develop stable replication competent Huh-7 cells containing GFP labeled sub-genomic HCV RNA. The availability of these cell lines allowed us to reliably quantify the antiviral effect of IFN- $\alpha$. A chimeric clone combining GFP and sub-genomic clone was prepared. As a control, GND mutant (pSGR-GND-GFP) for the replicon clone was also prepared. The full-cycle replication of pSGR-GFP RNA and unmodified pSGR-RNA in Huh-7 cells were compared for their ability to form cell colonies when cultured in the presence of a medium containing G-418 $(500 \mu \mathrm{g} / \mathrm{ml})$. In this assay, the cells supporting HCV RNA replication survived G-418 drug selection and formed cell colonies. No noticeable differences in the efficiency of replication of the sub-genomic RNA with or without GFP insertion in the NS5A region were observed based on the number of G-418 resistant 


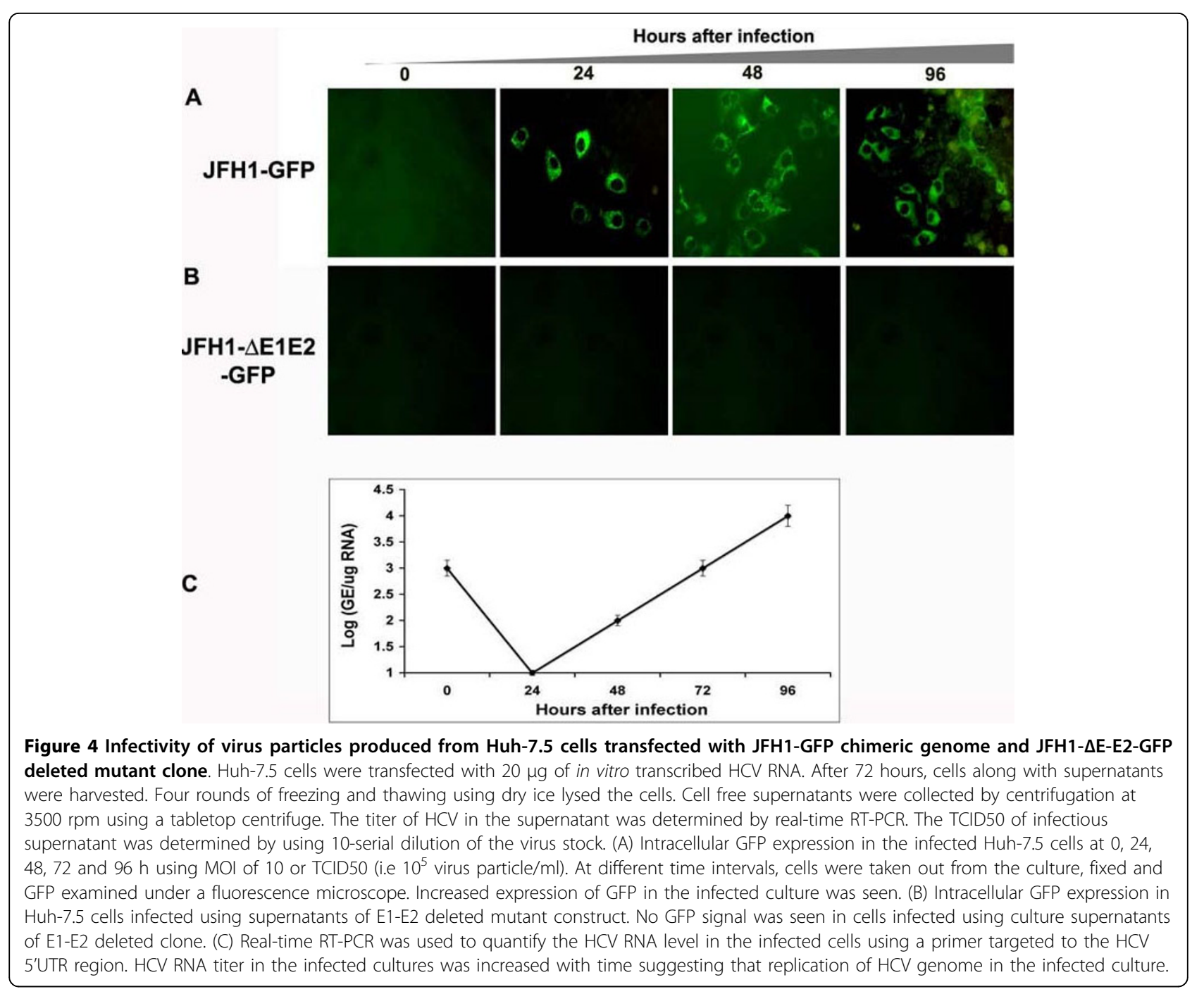

cell colonies that appeared on the plate (Fig. 5). No colonies developed in the culture transfected with the GND mutant sub-genomic HCV RNA. Individual cell colonies were picked and stable Huh-7 cell lines supporting replication of HCV-GFP sub-genomic RNA were developed. The absence of stable DNA integration in these cell lines was confirmed by direct PCR analysis for neo gene followed by southern blot analysis. High levels of GFP expression due to replication of sub-genomic HCV 2a clone was seen in sensitive and resistant Huh-7 clones (Fig. 6A). The expression of HCV-GFP chimera protein was seen exclusively in the cytoplasm in the majority of Huh-7 cells in the culture. These cell lines have maintained stable GFP expression over more than one year when cultured in a growth medium supplemented with G-418 $(500 \mu \mathrm{g} / \mathrm{ml})$. Two types of stable replicon cell lines were prepared using Huh-7 cells with or without functional Jak-Stat pathway. Stable HCVGFP replicon cell lines prepared using IFN sensitive (S-
Huh-7) cells were named as S3-GFP and S10-GFP replicons. Replicon cell lines, also prepared using IFN resistant Huh-7 cell lines (R-Huh-7), were named as R4-GFP and R8-GFP replicons. The level of GFP expression in the IFN sensitive and resistant replicon Huh-7 cell lines was quantitatively determined by flow analysis. The results of these experiments suggest that more than $80 \%$ of replicon cells express GFP (Fig. 6B).

\section{Antiviral activity of IFN- $\alpha$ against full-length HCV $2 \mathrm{a}$ is} blocked in Huh-7 cell clone (R-Huh 7) with a defective Jak-Stat pathway

The development of JFH1-GFP chimera using the HCV 2a clone allowed us to quantify the antiviral properties of IFN- $\alpha$ in Huh-7 cells. One important predictive factor associated with IFN response is the viral genotype. It has been reported by a number of investigators that the sustained virological response in patients infected with $\mathrm{HCV}$ genotype 2 is much higher than in patients 


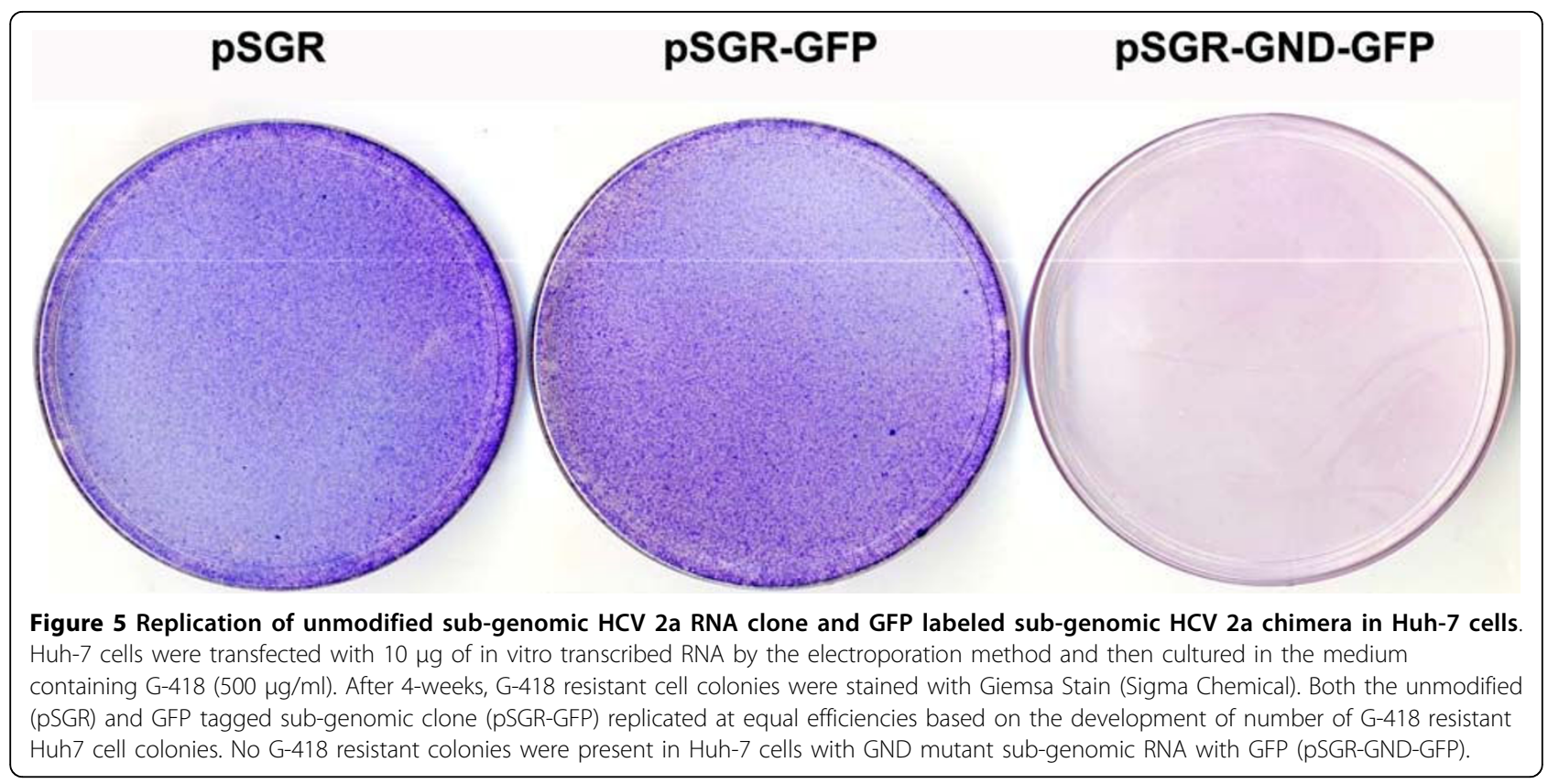

infected with genotype 1 virus. We conducted experiments to determine whether the replication of an $\mathrm{HCV}$ 2a strain could be inhibited in liver cells (R-Huh-7) having a defective Jak-Stat pathway. Both S-Huh-7 and RHuh-7 cells were transfected individually with fulllength JFH1-GFP RNA and then treated with an increasing concentration of IFN- $\alpha$. We first determined that both S-Huh-7 and R-Huh-7 cells developed in our laboratory supported HCV 2a replication and infection. The ability of IFN- $\alpha$ to inhibit full-length HCV 2a replication in these two different Huh-7 clones was examined in a kinetic study at 24 to 96 hours. Results shown in the upper panel of Fig. 7A suggest that GFP expression can be efficiently inhibited in S-Huh-7 cell clones. There was no reduction in GFP expression in the RHuh-7 cell clones with a defective Jak-Stat pathway at all time points (lower panel of Fig. 7A). The antiviral effect of IFN- $\alpha$ against HCV $2 a$ in these two cell clones (S-Huh-7 and R-Huh-7) was also quantified by flow cytometric analysis. We found a time dependent effect of IFN- $\alpha$ on HCV 2a replication in S-Huh-7 cells and the number of GFP positive cells was decreased from $4.2 \%$ to $0.2 \%$ as compared to resistant Huh- 7 cell line (Fig. 7B). To verify that the inhibition of GFP is also associated with the reduction of viral RNA in the interferon treated cells, RNA extracts were assayed for $\mathrm{HCV}$ RNA by RPA assay using a probe targeted to the 5' UTR region of $\mathrm{HCV}$ genome. We found that interferon treatment decreased HCV RNA levels in S-Huh-7 clones and the levels of HCV RNA remained unchanged after interferon treatment in the resistant clone. (Fig. 7C). The ability of IFN- $\alpha$ to stop viral RNA replication in the infected cells was also examined using these two Huh-7 cell clones. IFN- $\alpha$ treatment efficiently inhibited $\mathrm{HCV}$ replication as measured by GFP expression in SHuh-7 cells within 24 hours (Fig 8A). However, antiviral activity of IFN- $\alpha$ against the full-length HCV 2a replication was prevented in R-Huh-7 cells with the defective Jak-Stat pathway (Fig. 8B). The results of these experiments indicate that antiviral activity of IFN- $\alpha$ to inhibit replication of full-length $\mathrm{HCV} 2 \mathrm{a}$ clone was prevented in R-Huh-7 clone with defective Jak-Stat pathway.

Antiviral activity of IFN- $\alpha$ is impaired against HCV 2a subgenomic clone in Huh-7 cell clone with a defective JakStat pathway

The role of the Jak-Stat pathway in the IFN- $\alpha$ response to HCV 2a was also studied using an IFN sensitive (S3GFP) and IFN resistant (R4-GFP) stable Huh-7 cell line that replicates sub-genomic RNA. Replication of $\mathrm{HCV}$ 2a sub-genomic RNA in the S3-GFP after IFN- $\alpha$ treatment was studied by measuring the intracellular GFP expression directly under a fluorescence microscope. It was found that GFP expression in the stable cell line (S3-GFP) diminished over time (Fig 9A). Where as no reduction of the HCV-GFP signal in R4-GFP replicon was observed even when treated with a similar concentration of IFN- $\alpha$ for an extended period. To quantify the IFN antiviral effect intracellular GFP expression was analyzed by flow analysis. The GFP peak disappeared after IFN treatment only in the S3-GFP replicon cell line (53\% to $2 \%$ ). The percentage of GFP positive cells did not decrease ( $58 \%$ to $55 \%$ ) when similar experiments were carried out using R4-GFP cells (Fig. 9B). To 


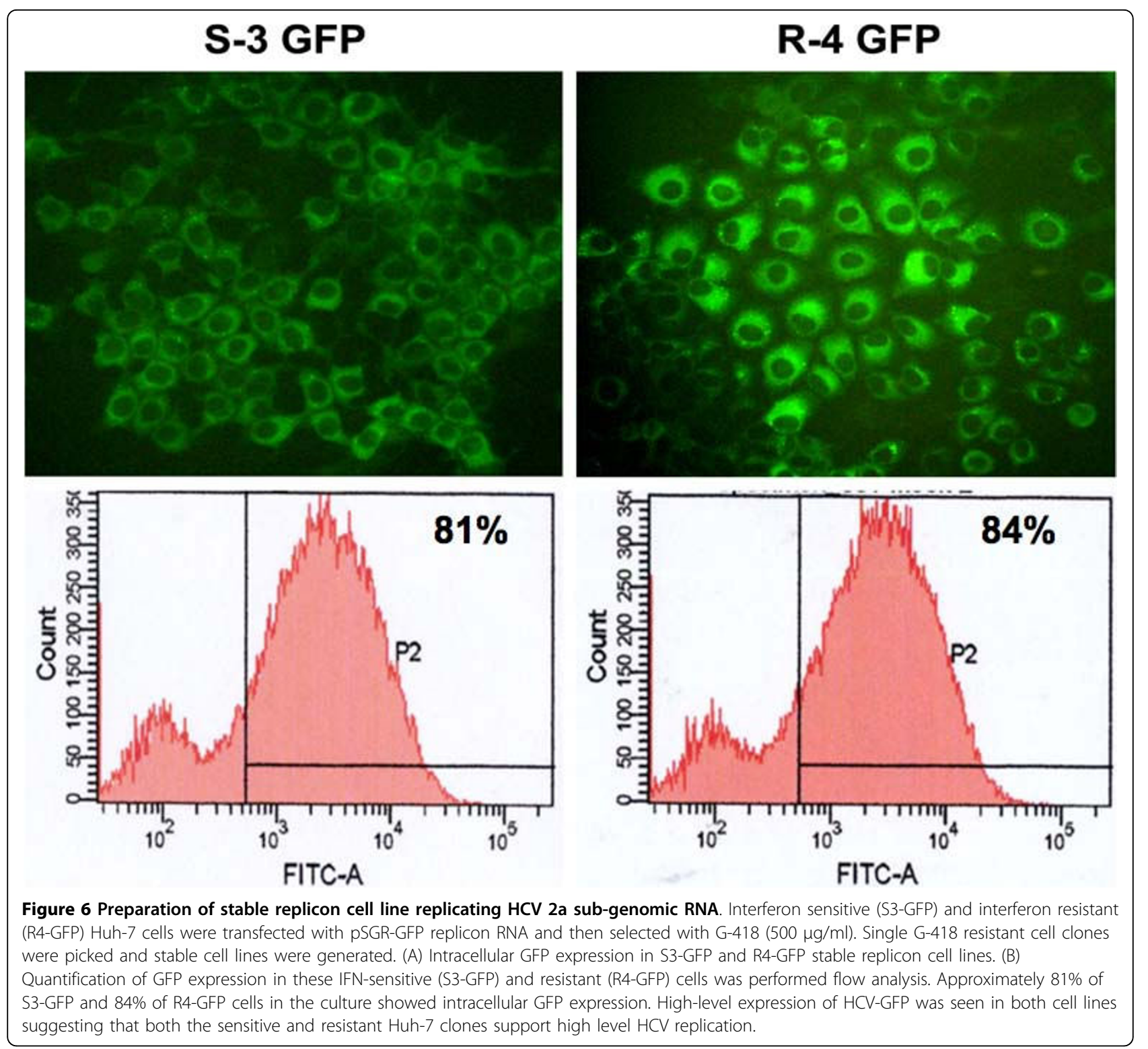

correlate the results of GFP expression, intracellular HCV RNA after IFN- $\alpha$ treatment was also measured by RPA. The results of RPA assays demonstrate that HCV RNA replication is not inhibited by IFN- $\alpha$ treatment in the R4-GFP replicon cell line (Fig. 9C). The level of HCV RNA was also quantified by real-time PCR in these two cell lines after IFN treatment. IFN- $\alpha$ treatment inhibited the HCV RNA level in a dose dependent manner in S3-GFP but the HCV RNA level remained the same in the R4-GFP replicon. There was a significant difference in the level of HCV RNA between the IFN sensitive replicon and resistant replicon after IFN treatment measured by real-time PCR (Fig. 9D). These results suggest that replication of $\mathrm{HCV} 2 \mathrm{a}$ full-length as well as sub-genomic RNA can not be inhibited by IFN$\alpha$ in R-Huh-7 cells with a defective Jak-Stat pathway.

HCV infection and replication did not alter the state of Jak-Stat pathway in S-Huh-7 and R-Huh-7 cell clones

Experiments were carried out to examine whether infection or replication of $\mathrm{HCV}$ in both S-Huh-7 and RHuh-7 cells could have any impact on the IFN- $\alpha$ induced Jak-Stat signaling. The levels of pStat 1 and pStat2 proteins in the lysates of S-Huh-7 and R-Huh-7 cells after 96 hours of HCV infection were examined by western blot analysis. Results shown in Fig. 10A and 10B clearly show that IFN- $\alpha$ treatment induced pStat1 and pStat 2 protein in the infected as well uninfected SHuh-7 only. However, pStat 1 or pStat 2 protein was not 


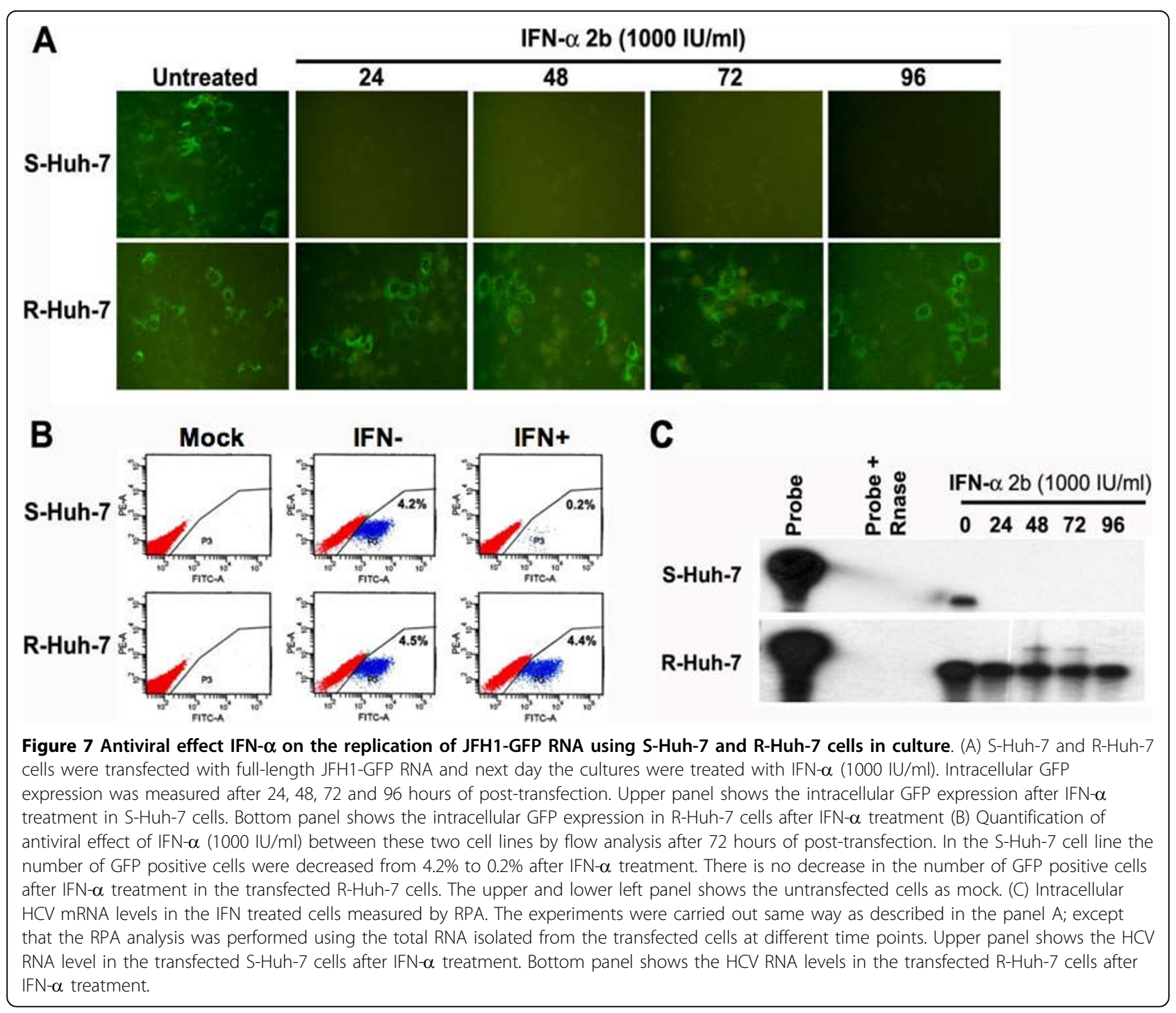

detected in the infected R-Huh-7 cells even after interferon treatment. These results were confirmed by a colocalization of pStat1 protein in the GFP labeled replicon cells after IFN-treatment. We show that pStat1 is induced only in the sensitive replicon (S3-GFP) and localizes to the nucleus. The nuclear translocation of pStat1 is correlated with a decrease in GFP expression after IFN- $\alpha$ at 72 hours in the S-Huh-7 cells only (Fig. $10 \mathrm{C})$. The pStat1 protein was undetectable in R4-GFP cells after IFN- $\alpha$ treatment. To examine if the effect of HCV infection or replication in both S-Huh-7 and RHuh-7 could alter the overall Jak-Stat signaling, the ISRE-luciferase promoter activity was examined by a transient transfection assay. Interferon induced activity of ISRE-luciferase did not change significantly in RHuh-7 cells after HCV infection (Fig. 10D).

\section{Discussion}

The JFH1 full-length cDNA clone of HCV 2a strain was isolated from a chronically infected Japanese patient by Wakita and his coworkers [14]. JFH1 derived clones replicate at a greater efficiency than all other $\mathrm{HCV}$ strains, making it the system of choice for biochemical studies that address HCV replication mechanisms and virus host interactions. The replication of full-length virus in cell culture is assessed by the detection of viral RNA by using a highly sensitive RT-PCR method. Viral proteins were detected by western blot analysis, ELISA or immunocytochemistry. These methods are highly specific and accurately determine the replication kinetics but are complex and time consuming. To overcome these difficulties, we prepared a chimeric clone of JFH1 by inserting the coding sequence of EGFP-N1 in the NS5A coding sequences. We noticed that a high-level 


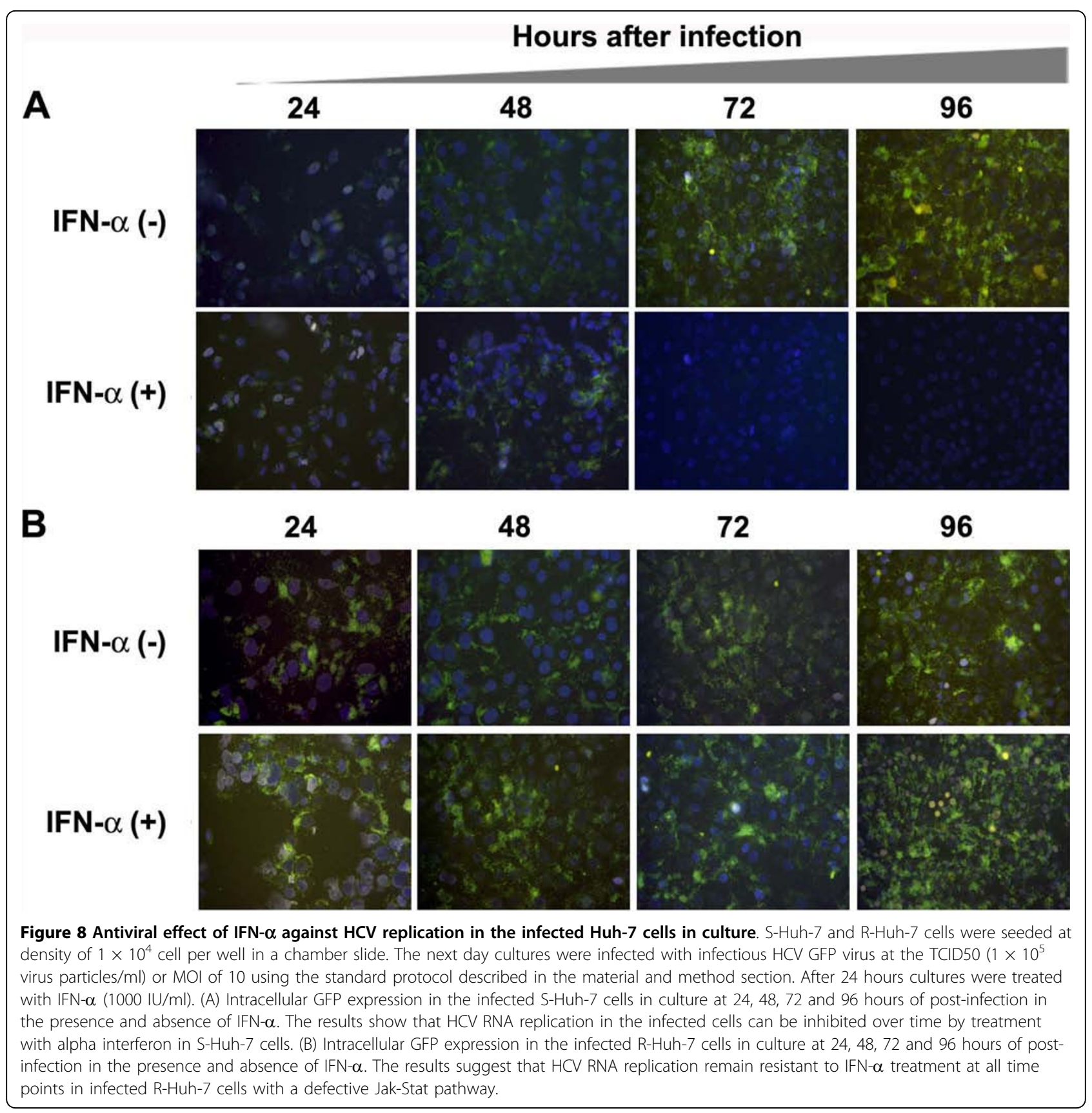

expression of this JFH1-GFP chimera was seen in Huh7.5 cells $24 \mathrm{~h}$ after transfection. The expression of GFP in the transfected cells is an indication of active replication of the HCV genome since no GFP expression was detected in cells transfected with a GND mutant RNA. Replication of JFH1-GFP RNA in the transfected cell is supported by the results of detection of positive and negative strand RNA. We also showed that the transfected cells produced infectious virus particles. The infection can be transferred to naïve Huh-7 cells in a culture. The expression of GFP protein and viral RNA increased over time in the infected culture suggest that the replication of $\mathrm{HCV}$ occurred over time after natural infection. We also prepared a JFH1 sub-genomic clone with GFP as a fusion protein. Multiple stable replicon cell lines containing the GFP chimeric clone and neomycin selection marker were prepared in Huh-7 cells. Replication of sub-genomic clone of HCV 2a in the Huh-7 cells was stable. High-level expression and replication of HCV sub-genomic RNA was observed in the cells for over one year, and can be assayed by flow analysis. Stable cell lines replicating HCV sub-genomic 


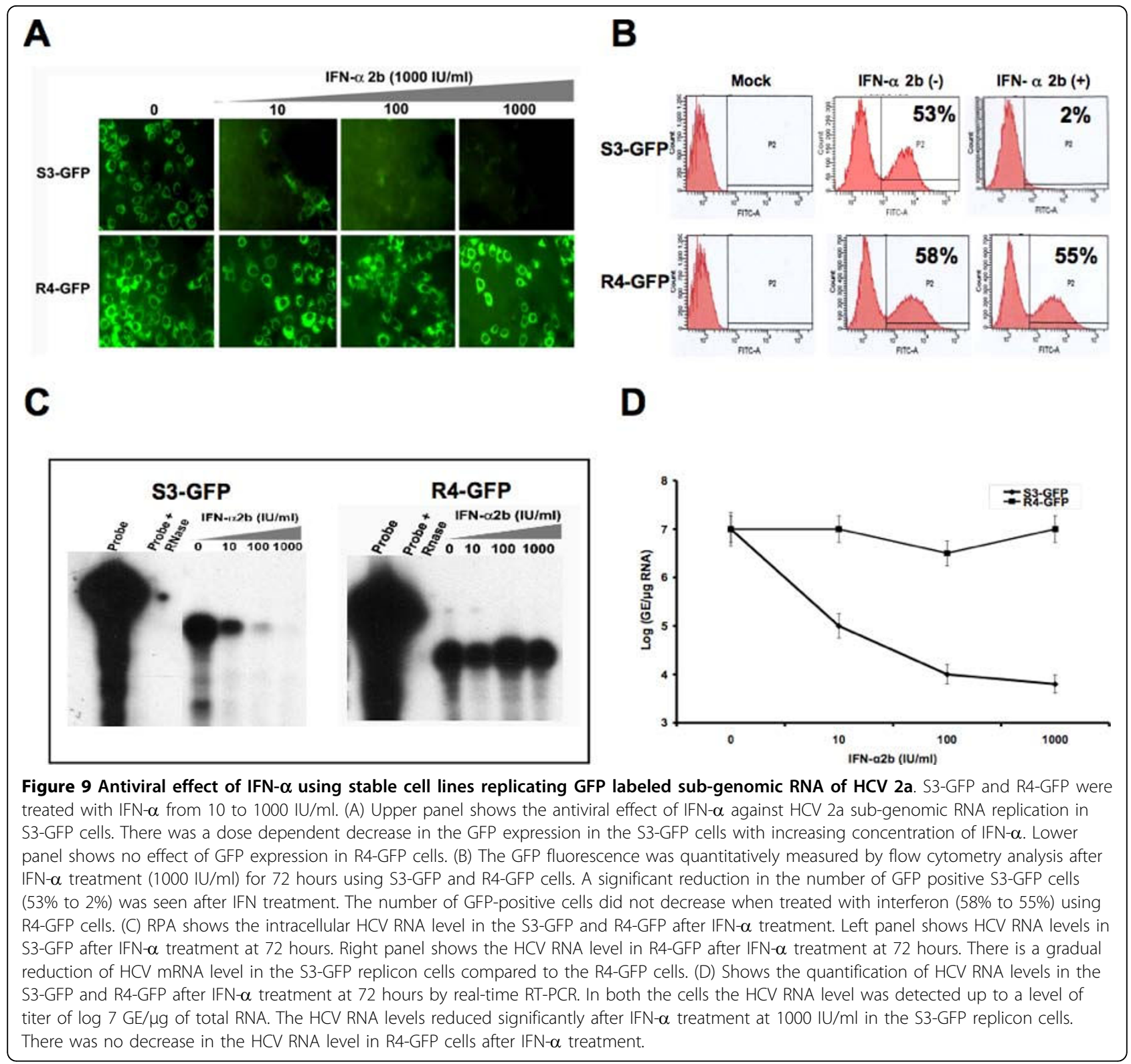

RNA were prepared using IFN-sensitive (S-Huh7) and resistant Huh-7 cells (R-Huh7). We now clearly showed that replication of HCV-GFP chimera cannot be inhibited by IFN- $\alpha$ in Huh-7 cells with defective Jak-Stat pathway.

The availability of a full-length GFP clone and stable replicon cell lines have allowed us to examine the antiviral mechanisms of IFN- $\alpha$ against HCV 2a strain in cell culture. There are reports suggesting that the effectiveness of the IFN response depends on the viral genotype. We performed a study to examine differences in the level of IFN response of HCV using the HCV 2a replication system. Previously, we have demonstrated that both the HCV 1a and HCV 1b strain can be efficiently inhibited by IFN- $\alpha$ within $72 \mathrm{~h}$ in a concentration dependent manner $[18,19]$. In this study we provide evidence suggesting that interferon alpha treatment inhibited HCV RNA replication of full-length as well as replication of HCV sub-genomic RNA in a dose dependent manner. These results are also consistent with a previous report suggesting that IFN inhibits replication of HCV $2 \mathrm{a}$ and HCV $1 \mathrm{~b}$ strain in a dose dependent manner [29]. The role of virus and the Jak-Stat pathway of host cell in the IFN response using HCV 2a cell culture system were examined. We showed here that IFN$\alpha$ treatment induced phosphorylation of Stat1 and Stat2 proteins in the infected S-Huh-7 cells and successfully inhibited HCV RNA replication. However, we could not 


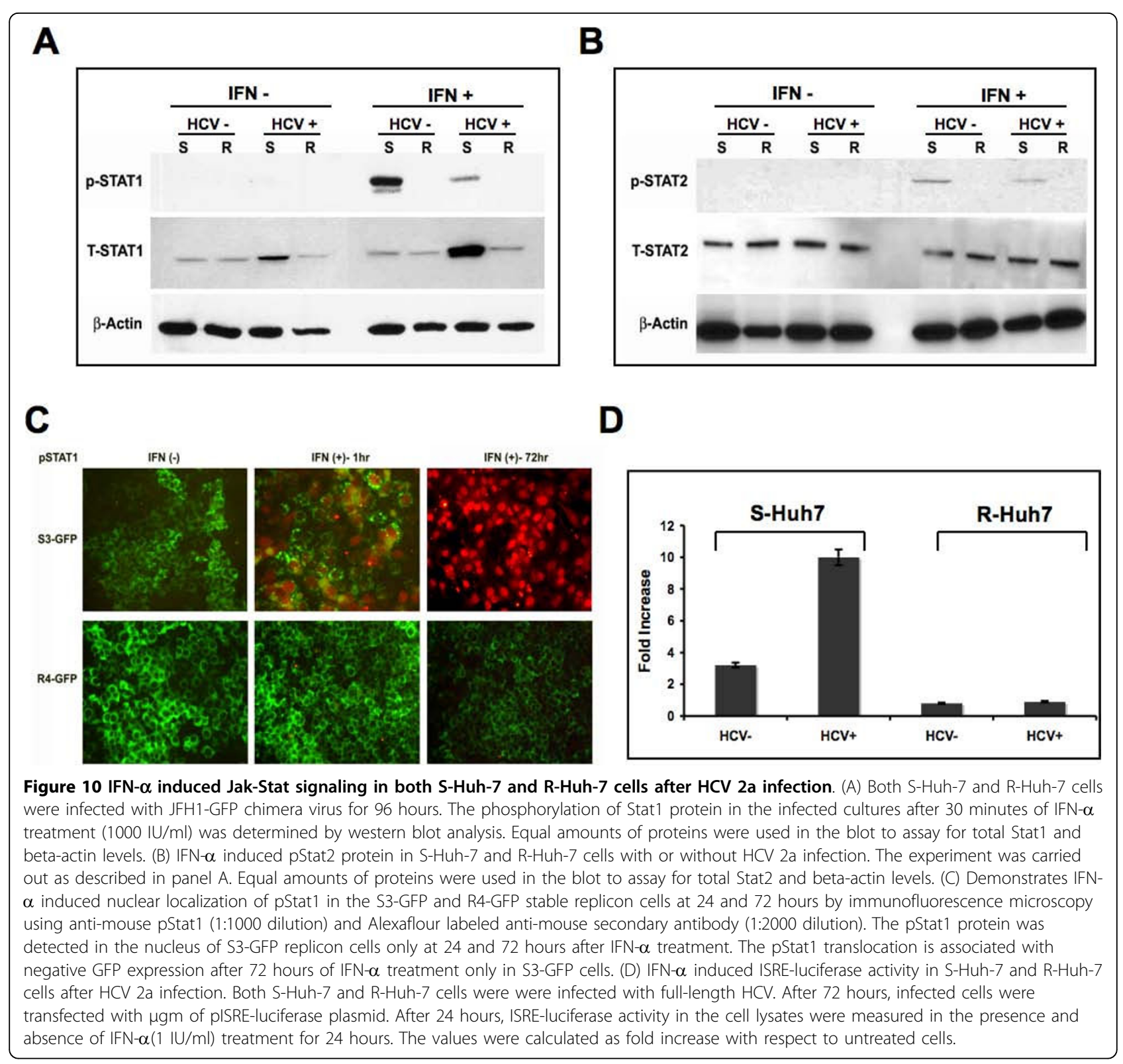

detect phosphorylated Stat1 or Stat 2 protein in the HCV infected R-Huh-7 cells after IFN- $\alpha$ treatment. The IFN$\alpha$ induced Jak-Stat mediated ISRE-luciferase activity of R-Huh-7 cells did not change significantly with or without HCV infection. We showed here that IFN- $\alpha$ is not able to inhibit the replication of full-length as well as sub-genomic HCV 2a virus in R-Huh-7 cell clone suggesting a dominant role of cellular Jak-Stat pathway in the response to the interferon treatment [22].

The overall sustained virological response of patients infected with $\mathrm{HCV}$ genotype 2 and 3 is about $80 \%$ as compared to only $50 \%$ in the case of chronic $\mathrm{HCV}$ patients that are infected with HCV genotype 1 strain [3]. The mechanisms that determine the response at the genotype level are not clear. There has been a report suggesting that the IFN treatment response alters two phases of viral replication kinetics [30]. The first phase is the dose dependent reduction of HCV RNA levels in the liver within the first 24 hours after treatment. The second phase of IFN-induced decline of HCV RNA occurs over weeks to months. The first phase viral decay may be due to the direct action of interferon on $\mathrm{HCV}$ production and the second phase may be due to death of infected cells. In our analysis, we have found that there is no difference in the efficacy of IFN upon replication of $\mathrm{HCV} 2 \mathrm{a}$ and $\mathrm{HCV}$ genotype $1 \mathrm{~b}$ viruses. It will be important to determine if there are differences in death of hepatocytes when they are infected with $\mathrm{HCV}$ 
genotype 1 and HCV 2a virus. Our study provides evidence suggesting that cells with defective Jak-Stat pathway of IFN-signaling can prevent the antiviral response after IFN- $\alpha$ treatment. This conclusion supports results from previous studies using HCV cell cultures [22,31] as well as by a recent multicenter study using clinical samples from HALT-C trial suggesting that response to IFN therapy is dependent upon the host genetic polymorphisms of Tyk2 in the liver cells [32]. In summary, results of this investigation support the importance of host cell factors in the mechanisms of IFN-resistance in chronic $\mathrm{HCV}$ infection. The development of IFN-sensitive and IFN-resistant GFP tagged HCV 2a replicon cell lines will allow us to further understand the mechanisms of resistance against $\mathrm{HCV}$ in tissue culture. In particular, GFP labeled IFN-resistant replicon cells should be very useful to develop alternative antiviral strategies to overcome IFN resistance against $\mathrm{HCV}$.

\begin{abstract}
Acknowledgements
We thank Jeanne Frois and Sakshi Kaul for critically reading the manuscript The authors thank Charlie Rice for providing the Huh-7.5 cell line, Ralf Bartenschlager for providing the 5-15 cell line, and Takaji Wakita for providing the JFH-1 and PSGR clone. The work was significantly delayed due to Hurricane Katrina, New Orleans, 2005. The authors thank the LSU Veterinary School, Baton Rouge, LA, for providing temporary laboratory space to rescue the IFN-sensitive and resistant Huh-7 cell clones during Hurricane Katrina in New Orleans. This work was supported by funds received from the National Cancer Institute (CA127481, CA129776-SD), (A 143000-GK), (DK070551-RFG), Louisiana Cancer Research Consortium (LCRC) and Tulane Cancer Center.
\end{abstract}

\section{Author details \\ ${ }^{1}$ Department of Pathology and Laboratory Medicine, Tulane University of Health Sciences Center, 1430 Tulane Ave, New Orleans, LA 70112, USA. ${ }^{2}$ Microbiology and Immunology, Tulane University of Health Sciences Center, 1430 Tulane Ave, New Orleans, LA 70112, USA. ${ }^{3}$ Division of Biotechnology and Molecular Medicine, School of Veterinary Medicine, Louisiana State University, Baton Rouge, LA 70803, USA. ${ }^{4}$ Department of Virology II, National Institute of Infectious Diseases, Tokyo, Japan.}

\section{Authors' contributions}

$\mathrm{SH}$ performed most of the biochemical experiments, prepared the chimeric constructs, cell lines, and participated in the design of the study. PKC contributed in the full-length infectivity assay. BP prepared RPA probe for negative strand detection and SND helped in western blot experiments. TPF and GK provided us the temporary laboratory space to recover the cell lines at the time of hurricane Katrina. TW provided the initial JFH1 constructs. RFG helped in editing the manuscript. SD overall supervised, helped to design the study and wrote the manuscript. All authors read and approved the final manuscript.

\section{Competing interests}

The authors declare that they have no competing interests.

Received: 20 November 2009

Accepted: 11 February 2010 Published: 11 February 2010

\section{References}

1. William R: Global challenges in liver disease. Hepatology 2006, 44:521-526.

2. Poynard T, Yuen MF, Ratziu V, Lai CL: Viral Hepatitis C. Lancet 2003, 362:2095-2100.

3. Ghanay MG, Strader DB, Thomas DL, Seeff LB: Diagnosis, management, and Treatment of hepatitis C: An update. Hepatology 2009, 49:1335-1374.
4. Webster DP, Klenerman P, Collier J, Jefffery KJM: Development of novel treatment for hepatitis C. Lancet Infect Dis 2009, 9:108-117.

5. Manns MP, Foster GR, Rockstroh JK, Zeuzem S, Zoulim F, Houghton M: The way forward in HCV treatment finding the right path. Nature Rev Drug Disco 2007, 6:991-1000.

6. Choo QL, Kuo G, Weiner AJ, Overby LR, Bradley DW, Houghton M: Isolation of a cDNA clone derived from a blood-borne non-A, non-B viral hepatitis genome. Science 1989, 244:359-362.

7. Moradpour D, Penin F, Rice CM: Replication of hepatitis C virus. Nature Review 2007, 5:453-463

8. Simmonds P: Genetic diversity and evolution of hepatitis $C$ virus- 15 years on. J Gen Virol 2004, 85:3173-88.

9. Bukh J, Miller RH, Purcell RH: Genetic heterogeneity of hepatitis C virus: quasispecies and genotypes. Semin Liver Dis 1995, 15:41-63.

10. Mahoney K, Tedeschi V, Maertens G, Di Bisceglie AM, Vergalla J, Hoofnagle $\mathrm{JH}$, Sallie R: Genetic analysis of hepatitis $\mathrm{C}$ virus in American patients. Hepatology 1994, 20:1405-1411.

11. Simmonds $P$, Mellor J, Sakuldamrongpanich T, Nuchaprayoon C, Tanprasert S, Holmes EC, Smith DB: Evolutionary analysis of variants of hepatitis $C$ virus found in South-East Asia: comparison with classifications based upon sequence similarity. J Gen Virol 1996, 77:3013-3024.

12. Sy T, Jamal MM: Epidemiology of Hepatitis C (HCV) infection. Int J Med Sciences 2006, 3:41-46.

13. Bartenschlager R: Hepatitis $C$ virus molecular clones: from cDNA to infectious virus particles in cell culture. Curr Opin Microbiol 2006, 9:416-422.

14. Wakita T, Pietschmann T, Kato T, Date T, Miyamoto M, Zhao Z, Murthy K, Habermann A, Krausslich HG, Mizokani M, Bartenschalager R, Liang TJ: Production of infectious hepatitis $C$ virus from a cloned viral genome. Nature Medicine 2005, 11:791-796.

15. Lindenbach BD, Evans MJ, Syder AJ, Wolk B, Tellinghuisen TL, Liu CC, Maruyama T, Hynes RO, Burton DR, McKeating JA, Rice CM: Complete Replication of hepatitis C virus in cell culture. Science 2005, 309:623-626.

16. Zhong J, Gastaminza P, Cheng G, Kapadia S, Kato T, Burton DR, Wieland SF, Uprichard SL, Wakita T, Chisari FV: Robust hepatitis C virus infection in vitro. Proc Natl Acad Sci 2005, 102:9294-9299.

17. Soriano V, Peters MG, Zeuzem S: New therapies for hepatitis $C$ virus infection. Clinical Infect Dis 2009, 48:313-320.

18. Dash S, Prabhu R, Hazari S, Bastian FO, Garry RF, Zou W, Haque S, Joshi V, Regenstein FG, Thung SN: Interferon alpha, beta, gamma each inhibits hepatitis $C$ virus replication at the levels of internal ribosome entry site mediated translation. Liver International 2005, 25:1-15.

19. Prabhu R, Joshi V, Garry RF, Bastian FO, Haque S, Regenstein F, Thung S, Dash S: Interferon alpha-2b inhibits negative-strand RNA and protein expression from full-length HCV1a infectious clone. Exp Mol Pathol 2004, 76:242-52.

20. Hazari S, Patel A, Prabhu R, Bastian FO, Garry RF, Joshi V, Haque S, Regenstein FG, Elliot R, Dash S: Interferon alpha inhibits internal ribosome entry site mediated translation of green fluorescence protein from six different HCV genotypes. J Gen Virol 2005, 86:3047-3053.

21. Pai M, R. Prabhu R, Panebra A, Nangle S, Bastian FO, Garry RF, Agrawal K, Goodbourn S, Dash S: Activation of interferon stimulated response element in a Huh-7 cell line replicating hepatitis $C$ virus sub-genomic RNA. Intervirology 2005, 48:301-311.

22. Hazari S, Taylor L, Haque S, Garry RF, Florman S, Luftig R, Regenstein F, Dash S: Reduced expression of Jak-1 and Tyk-2 proteins leads to interferon resistance in hepatitis C virus replicon. Virol J 2007, 4:89-102.

23. Kato T, Date T, Miyamoto M, Furusaka A, Tokushige K, Mizokami M, Wakita T: Efficient replication of the genotype $2 a$ hepatitis $C$ virus subgenomic replicon. Gastroenterology 2003, 125:1808-1817.

24. Gibellini D, Gardini F, Vitone F, Schiavone P, Furlini G, Carla Re M: Simultaneous detection of HCV and HIV- 1 by SYBR Green real time multiplex RT-PCR technique in plasma samples. Mol Cell Probes 2006, 20:223-229.

25. Moradpour D, Evans MJ, Gosert R, Yuan Z, Blum HE, Goff SP, Lindenbach $B D$, Rice $C M$ : Insertion of green fluorescence protein into non-structural protein $5 \mathrm{~A}$ allows direct visualization of functional hepatitis C virus replication complexes. J Virol 2004, 78:7400-7409. 
26. Koutsoudakis G, Kaul A, Steinmann E, Kallis S, Lohmann V, Pietschmann T, Bartenschalager R: Characterization of the early steps of hepatitis $C$ virus infection by using luciferase reporter viruses. J Virol 2006, 80:5308-5320.

27. Kim CS, Jung J-H, Wakita T, Yoon S-K, Jang S-K: Monitoring the antiviral effect of alpha interferon on individual cells. J Virol 2007, 81:8814-8820.

28. Schaller T, Appel N, Koutsoudakis G, Kallis S, Lohmann V, Pietschmann T, Bartenschlager R: Analysis of hepatitis $C$ virus super infection exclusion by using novel fluorochrome gene-tagged viral genome. J Virol 2007, 81:4591-4603

29. Miyamoto M, Kato T, Date T, Mizokami M, Wakita T: Comparison between sub-genomic replicons of hepatitis $\mathrm{C}$ virus genotypes $2 \mathrm{a}(\mathrm{JFH}-1)$ and $1 \mathrm{~b}$ (Con1 NK5.1). Intervirology 2006, 49:37-43.

30. Neumann AU, Lam Dahari NOH, Gretch DR, Wiley TE: Hepatitis C viral dynamics in vivo and the antiviral efficacy of interferon-alpha therapy. Science 1998, 282:103-107.

31. Naka K, Takemoto K, Abe K, Dansako H, Ikeda M, Shimotohno K, Kato N: Interferon resistance of hepatitis $C$ virus replicon-harbouring cells is caused by functional disruption of type 1 interferon receptors. $J$ Gen Virol 2005, 86:2787-2792.

32. Welzel TM, Morgan TR, Bonkovsky HL, Naishadham D, Pfeiffer RM, Wright EC, Hutchinson AA, Crenshaw AT, Bashirova A, Corrington M: Variants in Interferon-alpha pathway genes and response to pegylated interferon-alpha 2a plus ribavirin for treatment of chronic hepatitis $C$ virus infection in the hepatitis $C$ Antiviral Long-term treatment against Cirrhosis trial. Hepatology 2009, 49:1847-1858.

doi:10.1186/1743-422X-7-36

Cite this article as: Hazari et al: Impaired antiviral activity of interferon alpha against hepatitis $C$ virus $2 a$ in Huh-7 cells with a defective JakStat pathway. Virology Journal 2010 7:36.

\section{Submit your next manuscript to BioMed Central and take full advantage of:}

- Convenient online submission

- Thorough peer review

- No space constraints or color figure charges

- Immediate publication on acceptance

- Inclusion in PubMed, CAS, Scopus and Google Scholar

- Research which is freely available for redistribution

Submit your manuscript at www.biomedcentral.com/submit 